Pacific Journal of Mathematics

OTE ON NoRMaL Noumbres 


\section{NOTE ON NORMAL NUMBERS}

\section{Calvin T. Long}

Introduction. Let $\alpha$ be a real number with fractional part.$a_{1} a_{2} a_{3} \ldots$ when written to base $r$. Let $Y_{n}$ denote the block of the first $n$ digits in this representation and let $N\left(d, Y_{n}\right)$ denote the number of occurrences of the digit $d$ in $Y_{n}$. The number $\alpha$ is said to be simply normal to base $r$ if

$$
\lim _{n \rightarrow \infty} \frac{N\left(d, Y_{n}\right)}{n}=\frac{1}{r}
$$

for each of the $r$ distinct choices of $\alpha . \quad \alpha$ is said to be normal to base $r$ if each of the numbers $\alpha, r \alpha, r^{2} \alpha, \cdots$ are simply normal to each of the bases $r, r^{2}, r^{3}, \ldots$. These definitions, due to Emile Borel [1], were introduced in 1909. In $1940 \mathrm{~S}$. S. Pillai [3] showed that a necessary and sufficient condition that $\alpha$ be normal to base $r$ is that it be simply normal to each of the bases $r, r^{2}, r^{3}, \cdots$, thus considerably reducing the number of conditions needed to imply normality. The purpose of the present note is to show that $\alpha$ is normal to base $r$ if and only if there exists a set of positive integers $m_{1}<m_{2}<m_{3}<\cdots$ such that $\alpha$ is simply normal to base $r^{m_{i}}$ for each $i \geq 1$, and also to show that no finite set of $m$ 's will suffice.

Notation. We make use of the following additional conventions.

If $B_{k}$ is any block of $k$ digits to base $r, N\left(B_{k}, Y_{n}\right)$ will denote the number of occurrences of $B_{k}$ in $Y_{n}$ and $N_{i}\left(B_{k}, Y_{n}\right)$ will denote the number of occurrences of $B_{k}$ starting in positions congruent to $i$ modulo $k$ in $Y_{n}$.

The term "relative frequency" will denote the asymptotic frequency with which an event occurs. For example, $B_{k}$ occurs in $(\alpha)$, the fractional part of $\alpha$, with relative frequency $r^{-k}$ if $\lim _{n \rightarrow \infty} N\left(B_{k}, Y_{n}\right) / n=r^{-k}$.

Proof of the theorems. The following lemmas are easily proved.

LEMMa 1. If $\lim _{n \rightarrow \infty} \sum_{i=1} f_{i}(n)=1$ and if $\lim _{n \rightarrow \infty} \inf f_{i}(n) \geqq 1 / m \quad$ for $i=1,2, \cdots, m$; then $\lim _{n \rightarrow \infty} f_{i}(n)=1 / m$ for each $i$.

LEMMA 2. The real number $\alpha$ is simply normal to base $r^{k}$ if and

Received July 5, 1956. Results in this paper were included in a doctoral dissertation written under the direction of Professor Ivan Niven at the University of Oregon. 1955. 
only if $\lim _{n \rightarrow \infty} N_{1}\left(B_{k}, Y_{n}\right) / n=1 / k r^{k}$ for every block $B_{k}$ of $k$ digits to base $r$.

THEOREM 1. The real number $\alpha$ is normal to base $r$ if and only if there exist positive integers $m_{1}<m_{2}<m_{3}<\cdots$ such that $\alpha$ is simply normal to each of the bases $r^{m_{1}}, r^{m_{2}}, r^{m_{3}}, \cdots$.

Proof. The necessity of the condition follows immediately from the definition of normality.

Now suppose the condition of the theorem prevails. Let $\nu$ be an arbitrary positive integer and let $B_{\nu}$ be an arbitrary block of $\nu$ digits to base $r$. Choose $k$ so large that $m_{k}>\nu$. It follows from Lemma 2 that

$$
\lim _{n \rightarrow \infty} \frac{N_{1}\left(A_{m_{k}}, Y_{n}\right)}{n}=\frac{1}{m_{k} r^{m_{k}}}
$$

for each block $A_{m_{k}}$ of $m_{k}$ digits to base $r$. If $B_{\nu}$ occurs exactly $t=t\left(A_{m_{k}}\right)$ times in each $A_{m_{k}}$, then it follows that

$$
\liminf _{n \rightarrow \infty} \frac{N\left(B_{\nu}, Y_{n}\right)}{n} \geqq \frac{T}{m_{k} r^{m_{k}}}
$$

where $T=\sum t\left(A_{m_{k}}\right)$ with the sum running over all blocks of $m_{k}$ digits to base $r$. Now there are $r^{m_{k}-\nu}$ distinct blocks $A_{m_{k}}$ which contain $B$. starting in position $i$ for $i=1,2, \cdots, m_{k}-\nu+1$ so that $T=\left(m_{k}-\nu+1\right) r^{m_{k}-\nu} \nu$ Thus it follows that

$$
\liminf _{n \rightarrow \infty} \frac{N\left(B_{\nu}, Y_{n}\right)}{n} \geqq \frac{\left(m_{k}-\nu+1\right) r^{m_{k}-\nu}}{m_{k} r^{m_{k}}}=\frac{1}{r^{\nu}}-\frac{\nu-1}{m_{k} r^{\nu}} .
$$

But, since this argument can be made for arbitrarily large values of $k$ and $m_{k} \geqq k$, this implies that

$$
\liminf _{n \rightarrow \infty} \frac{N\left(B_{\nu}, Y_{n}\right)}{n} \geqq \frac{1}{r^{\nu}} .
$$

With Lemma 1 this implies that

$$
\lim _{n \rightarrow \infty} \frac{N\left(B_{\nu}, Y_{n}\right)}{n}=\frac{1}{r^{2}}
$$

so that $\alpha$ is normal to base $r$ by a result of Niven and Zuckerman [2]. The next theorem implies that no finite set of $m$ 's will suffice in Theorem 1.

THEOREM 2. If $m_{1}, m_{2}, \cdots, m_{s}$ is an arbitrary collection of distinct 
positive integers, then there exists at least one real number $\alpha$ simply normal to each of the bases $r^{m_{1}}, r^{m_{2}}, \cdots, r^{m_{s}}$ but not normal to base $r$.

Proof. Writing to base $r^{m}$ form the periodic decimal

$$
\alpha=. \dot{0} 12 \ldots\left(r^{\dot{m}}-1\right)
$$

where $m$ is the least common multiple of $m_{1}, m_{2}, \cdots, m_{s}$. It is clear that $\alpha$ is simply normal to base $r^{m}$ and that it is not normal to base $r$. To show that it is simply normal to base $r^{m_{i}}$ for $i=1,2, \cdots, s$ we prove that if $d$ divides $m$ then $\alpha$ is simply normal to base $r^{d}$.

Let $m=q d$ and let $B_{d}$ be an arbitrary but fixed block of $d$ digits to base $r$. In view of Lemma 2 it suffices to show that

$$
\lim _{n \rightarrow \infty} \frac{N_{1}\left(B_{a}, Y_{n}\right)}{n}=\frac{1}{d r^{d}}
$$

A simple counting process shows that there are precisely $\left(\begin{array}{l}q \\ i\end{array}\right)\left(r^{d}-1\right)^{q-i}$ distinct blocks $A_{m}$ of $m$ digits to base $r$ which contain $B_{d}$ exactly $i$ times starting in a position congruent to one modulo $d$. Therefore, since

$$
\lim _{n \rightarrow \infty} \frac{N_{1}\left(A_{m}, Y_{n}\right)}{n}=\frac{1}{m r^{m}}
$$

for each $A_{m}$, it follows that

$$
\lim _{n \rightarrow \infty} \frac{N_{1}\left(B_{d}, Y_{n}\right)}{n}=\frac{1}{m r^{m}} \sum_{i=1}^{q} i\left(\frac{q}{i}\right)\left(r^{d}-1\right)^{q-i}=\frac{1}{d r^{d}}
$$

as required.

\section{REFERENCES}

1. Émile Borel, Les probabilités dénombrablés et leurs applications arithmétiques, Rend. Circ. Mat. Palmero 27 (1909), 247-271.

2. Ivan Niven and H. S. Zuckerman, On the definition of normal numbers, Pacific J. Math., 1 (1951), 103-109.

3. S. S. Pillai, On normal numbers, Proc. Indian Acad. Sci., Sect. A, 12 (1940), 179-184. 



\section{PACIFIC JOURNAL OF MATHEMATICS}

\section{EDITORS}

H. L. ROYDEN

Stanford University

Stanford, California

R. A. Beaumont

University of Washington

Seattle 5, Washington

\section{A. L. Whiteman}

University of Southern California

Los Angeles 7, California

E. G. Straus

University of California

Los Angeles 24, California

\section{ASSOCIATE EDITORS}
E. F. BECKENBACH
C. E. BURGESS
M. HALL
E. HEWITT

\author{
A. HORN \\ V. GANAPATHY IYER \\ R. D. JAMES \\ M. S. KNEBELMAN
}

L. NACHBIN

I. NIVEN

G. SZEKERES

T. G. OSTROM

M. M. SCHIFFER
F. WOLF

K. YOSIDA

\section{SUPPORTING INSTITUTIONS}

\author{
UNIVERSITY OF BRITISH COLUMBIA \\ CALIFORNIA INSTITUTE OF TECHNOLOGY \\ UNIVERSITY OF CALIFORNIA \\ MONTANA STATE UNIVERSITY \\ UNIVERSITY OF NEVADA \\ OREGON STATE COLLEGE \\ UNIVERSITY OF OREGON \\ UNIVERSITY OF SOUTHERN CALIFORNIA
}

\author{
STANFORD UNIVERSITY \\ UNIVERSITY OF UTAH \\ WASHINGTON STATE COLLEGE \\ UNIVERSITY OF WASHINGTON \\ AMERICAN MATHEMATICAL SOCIETY \\ CALIFORNIA RESEARCH CORPORATION \\ HUGHES AIRCRAFT COMPANY \\ THE RAMO-WOOLDRIDGE CORPORATION
}

Mathematical papers intended for publication in the Pacific Journal of Mathematics should be typewritten (double spaced), and the author should keep a complete copy. Manuscripts may be sent to any of the editors. All other communications to the editors should be addressed to the managing editor, E. G. Straus at the University of California, Los Angeles 24, California.

50 reprints per author of each article are furnished free of charge; additional copies may be obtained at cost in multiples of 50 .

The Pacific Journal, of Mathematics is published quarterly, in March, June, September, and December. The price per volume (4 numbers) is $\$ 12.00$; single issues, $\$ 3.50$. Back numbers are available. Special price to individual faculty members of supporting institutions and to individual members of the American Mathematical Society: $\$ 4.00$ per volume; single issues, $\$ 1.25$.

Subscriptions, orders for back numbers, and changes of address should be sent to Pacific Journal of Mathematics, 2120 Oxford Street, Berkeley 4, California.

Printed at Kokusai Bunken Insatsusha (International Academic Printing Co., Ltd.), No. 10, 1-chome, Fujimi-cho, Chiyoda-ku, Tokyo, Japan.

PUBLISHED BY PACIFIC JOURNAL OF MATHEMATICS, A NON-PROFIT CORPORATION

The Supporting Institutions listed above contribute to the cost of publication of this Journal, but they are not owners or publishers and have no responsibility for its content or policies. 


\section{Pacific Journal of Mathematics}

\section{Vol. 7, No. 2 \\ February, 1957}

William F. Donoghue, Jr., The lattice of invariant subspaces of a completely continuous quasi-nilpotent transformation ................... 1031

Michael (Mihály) Fekete and J. L. Walsh, Asymptotic behavior of restricted extremal polynomials and of their zeros.................... 1037

Shaul Foguel, Biorthogonal systems in Banach spaces ............... 1065

David Gale, A theorem on flows in networks ................... 1073

Ioan M. James, On spaces with a multiplication .................. 1083

Richard Vincent Kadison and Isadore Manual Singer, Three test problems in operator theory .................................... 1101

Maurice Kennedy, A convergence theorem for a certain class of Markoff processes........................................ 1107

G. Kurepa, On a new reciprocity, distribution and duality law ........ 1125

Richard Kenneth Lashof, Lie algebras of locally compact groups ........ 1145

Calvin T. Long, Note on normal numbers .................... 1163

M. Mikolás, On certain sums generating the Dedekind sums and their reciprocity laws ..................................... 1167

Barrett O'Neill, Induced homology homomorphisms for set-valued maps......................................... 1179

Mary Ellen Rudin, A topological characterization of sets of real numbers........................................... 1185

M. Schiffer, The Fredholm eigen values of plane domains 1187

F. A. Valentine, A three point convexity property .........

Alexander Doniphan Wallace, The center of a compact lattice is totally

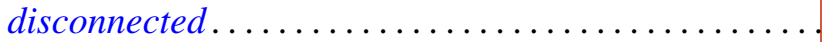

Alexander Doniphan Wallace, Two theorems on topological lattices.

G. T. Whyburn, Dimension and non-density preservation of mappings...

John Hunter Williamson, On the functional representation of certain algebraic systems ... 